\title{
Abstração refletida presente na aprendizagem cooperativa medida pelo espaço de aprendizagem digital da Matemática
}

\author{
Abstraction Reflected in cooperative learning settings mediated by a digital learning \\ mathematics space
}

\author{
Aline Silva De Bona \\ Instituto Federal de Educação, Ciência e Tecnologia \\ do Rio Grande do Sul (IFRS) - Campus Osório \\ aline.bona@osorio.ifrs.edu.br
}

\author{
Marcus Vinicius de Azevedo Basso \\ Universidade Federal do Rio Grande do Sul \\ mbasso@ufrgs.br
}

\begin{abstract}
Resumo O estudo é um recorte da pesquisa-ação de doutorado na área da Informática na Educação Matemática, realizada em 2012, no IFRS - Campus Osório com estudantes do ensino médio, que tem o objetivo de apresentar dois elementos atrativos aos estudantes para aprender a aprender matemática: espaço de aprendizagem digital da matemática, adotado o Facebook, e a aprendizagem cooperativa, e também evidenciar a presença da abstração refletida na construção de uma generalização/demonstração matemática. Analisa-se a resolução de problemas de matemática à luz da teoria de Piaget, e conclui-se a possibilidade de se compreender o processo de construção dos conceitos de matemática, além da sua aprendizagem por consciência dos estudantes.
\end{abstract}

Palavras-Chave: Tecnologias Digitais online, Cooperação, Espaço de Aprendizagem Digital, Educação Matemática.

\begin{abstract}
This study is part of a research-action approach in the field of Information Technology in Mathematics Education, held in 2012 at IFRS - Campus Osório, with high school students. We aims to present two attractive elements for students to learn how to learn math: space of digital learning math, namely Facebook, and cooperative learning. We highlight the presence of abstraction reflected in the construction of generalizations and mathematical demonstrations. We analyze the student's math problem solving approach in light of Piaget's theory, and conclude the possibility of understanding the construction process of math concepts and awareness of students.
\end{abstract}

Keywords: Digital Technologies online, Cooperation, Digital Learning Space, Mathematics Education. 


\section{Introdução}

O texto começa aqui. A aprendizagem de matemática e o uso das tecnologias digitais online como recurso para esta aprendizagem é uma temática importante apontada por Fiorentini e Lorenzato (2007)[16]. No entanto, existe a necessidade de pesquisas que apontem práticas docentes de como abordar estar tecnologias digitais online em sala de aula na escola básica, e não apenas constatações de que estes recursos são benéficos para educação matemática, como sustentam tais autores.

Colaboram com estas ideias sobre a educação matemática aos jovens de hoje, as pesquisas de: Fagundes (1993)[15]; Valente (2001)[34]; Basso (2003)[3]; Morais (2010)[21]; Serres (2010)[31]; Hoffman (2011)[19]; Bona $(2010,2012)[4,5]$, Borba e Penteado (2011)[9], em âmbito nacional, já internacionalmente cita-se, algumas com: Spauding e Lake (1992)[32]; Papert (1994)[25]; Grieneski (1999)[18]; Ribeiro e Ponte (2000)[30]; Goos et al (2003)[17]; Trouche (2003)[33]; Borba e Villarreal (2005)[10]; Peters (2009)[26]; Palfrey e Gasser (2011)[24].

Além disso, tanto na fala de professores se faz presente a menção de que os estudantes não querem aprender matemática, como: Camargo e Bampi (2011)[12], Bona $(2012$; 2013)[5,2], que não se interessam pelas aulas, como nas avaliações externas à escola (INEP, 2011)[20], estão visíveis os baixos desempenhos escolares dos estudantes quanto à matemática.

Assim, se é preciso pesquisar como atrair estes estudantes para participar das aulas de matemática e dai conquistar a curiosidade destes estudantes para aprender a aprender matemática fazendo uso de meios e formas que lhe são interessantes. Então, o objetivo deste artigo é de apresentar dois elementos atrativos aos estudantes para aprender a aprender matemática: espaço de aprendizagem digital da matemática, e a aprendizagem cooperativa. E também evidenciar a presença da abstração refletida na construção de uma generalização/demonstração matemática. Tendo como questão deste artigo: De que formas e meios pode-se mobilizar e analisar, segundo a abstração reflexionante de Piaget (1977)[29], os estudantes a aprender a aprender os conceitos de Matemática na Escola Básica?

Sendo estes elementos resultados de uma pesquisa-ação de doutorado realizada na Universidade Federal do Rio Grande do Sul (UFRGS) - Programa de PósGraduação em Informática na Educação (PPGIE) por um dos autores deste artigo, em 2012, no Instituto Federal de
Educação, Ciência e Tecnologias do Rio Grande do Sul (IFRS) - Campus Osório, com 24 estudantes do ensino médio integrado em informática, onde o espaço de aprendizagem digital da matemática adotado por esta turma foi a rede social Facebook.

Os dados analisados nesta pesquisa, e, consequentemente, neste artigo são as resoluções de problemas de matemática à luz da teoria de Piaget, principalmente os Estudos Sociológicos e a Abstração reflexionante, e conclui-se a possibilidade de se compreender o processo de construção dos conceitos de matemática, além da sua aprendizagem por consciência dos estudantes. Cade destacar que além das pesquisas de Bona (2012; 2013)[5,2], que articula as Tecnologias Digitais Online a teoria de Piaget, existem duas referências, uma nacional e outra internacional, respectivamente, que também colaboram com esta articulação, que são: Nogueira e Pavanello (2008)[23] e Dubinsky e Lewin (1986)[14].

O artigo está organização nas seguintes seções: introdução, elementos atrativos ao aprender a aprender matemática, método e material, abstração refletida presente na generalização de matemática, considerações finais e referências bibliográficas.

\section{Elementos atrativos ao aprender a aprender matemática}

A pesquisa-ação realizada por Bona (2012)[5] apresenta e defini dois elementos atrativos aos estudantes no processo de aprender a aprender matemática que são: o espaço de aprendizagem digital e a aprendizagem cooperativa.

O espaço de aprendizagem digital da matemática é um espaço de aprendizagem virtual e um local não situado geograficamente onde o processo de ensinoaprendizagem ocorre através da organização e aplicação de uma concepção pedagógica, baseada na comunicação, interação, trabalho colaborativo do professor com os estudantes, e cooperativos dos estudantes entre si e com o professor, segundo Bona, Fagundes, Basso (2011)[6]. Para Peters (2009)[26], existem outros espaços virtuais que não são de aprendizagem devido à ausência de concepção pedagógica e assim de aprendizagem.

Este espaço exige um recurso fundamental para possibilitar a interação entre todos os estudantes que é a comunicação assíncrona disponibilizada via chat. E mais este chat deve ficar salvo e disponibilizado a todos os estudantes e ao professor para todos os agentes do processo de aprendizagem possam pesquisar, informar-se, 
construir, e fazer junto. Como pesquisa é através desse chat que se faz viável a constatação da reflexão do estudante a cada passo da resolução de um problema de matemática.

O espaço de aprendizagem digital da matemática adotado em 2012 no IFRS-Campus Osório foi a rede social Facebook por contemplar a definição acima, e ser escolhido pelos estudantes por sua dinamicidade e também por ferramentas como: chat, aplicativos de anexo de documentos denominado Docs, eventos usados como agenda, além da sua disposição como fórum, garantia de armazenamento de dados, e o fácil compartilhamento de links, vídeos e outras mídias e multimídias, inclusive com construções do Geogebra. Destaca-se que antigamente se usava o Orkut, hoje se usa o Facebook, mas o essencial é o recurso digital online como o fórum que se destaca como atrativo neste artigo.

Cabe destacar que a ausência de hierarquia no $F a$ cebook é um fato importante a autonomia e responsabilização do processo de aprendizagem pelos estudantes, e também, é desta ausência de poderes que se estabelecer a primeira condição de paridade entre a professora e os estudantes para se iniciar um processo de cooperação. A outra condição necessária para se usar uma rede social como espaço de aprendizagem digital e para nesta rede ser possível uma aprendizagem cooperativa (explicada a seguir) é o contrato didático.

O contrato didático ou disciplinar consiste num conjunto de direitos e deveres dos estudantes e professora na sala de aula presencial e online (espaço do Facebook) construídas coletivamente nos primeiros dias de aula, segundo Bona (2010)[4], e este documento é assinado pelos estudantes e pelos pais/responsáveis destes. A estratégia do contrato didático é apontada por Chevallard (1991)[10] como uma situação didática que possibilita uma interação entre estudantes e professor, onde as regras de funcionamento das aulas/atividades são plenamente entendidas por todos.

A finalidade do contrato é que todos participem ativamente do seu processo de aprendizagem e entendam que somos um coletivo, e que precisamos viver em harmonia com as pessoas em sala de aula e em casa, para assim atingir objetivo de estar na escola que é aprender a aprender, além de se socializar como um cidadão.

A aprendizagem mediada pelas tecnologias digitais online estão alicerçadas na interação, e na interatividade, segundo Bona, Fagundes, Basso (2012a,b)[7,8], e desta leitura de processo de aprendizagem surge os conceitos de colaboração e cooperação, como método de trabalho/pesquisa/ação e como forma de aprendizagem.
A pesquisa-ação é um método de pesquisa colaborativo em que a ideia de colaboração primeiramente é uma divisão de atividades com um objetivo comum, mas cada qual com sua especificidade. Já a cooperação, para Piaget (1973)[28], é a interação estruturada no respeito mútuo e na autonomia de regras, ou seja, para cooperar é necessário operar em comum, respeitando suas diferenças, mas primando pela correspondência, complementariedade e reciprocidade dos pontos de vista, no caso da matemática de cada passo da resolução de um problema.

A cooperação quer do estudante diversos momentos de reflexão, tanto em interação com os colegas ou objeto ou consigo mesmo, e desta se observa a abstração do estudante nas suas ações.

Para Piaget (1977)[27], ao fazer e compreender um problema de matemática, o estudante reorganiza inúmeros esquemas e conceitos em busca da resolução, que são abstrações. Tais abstrações podem ser empíricas, reflexionantes e/ou refletidas, sendo três tipos diferentes que serão diferenciados a seguir no artigo.

A abstração empírica se apoiava sobre os objetos físicos e materiais da própria ação, sendo em Matemática muito comum a associação aos sólidos, por exemplo, em geometria espacial, e/ou ao manusear um sólido concluir da sua ação que este tem arestas iguais, ou outras informações.

Já a abstração reflexionante, em seus diferentes patamares de reflexionamento, percorre quase todas as ações dos estudantes enquanto resolvem um problema de Matemática, variando de um patamar mais simples ao mais complexo, como exemplo: ao resolver um problema de geometria sobre o calculo de volume de um paralelepípedo, um estudante primeiro precisa verificar se tem a informações necessárias para calcular, e depois qual a técnica-operação precisa realizar, mas se o estudante fizer sem verificar se as unidades de medida são as mesmas, encontrara uma resposta sem sentido ao problema, mas conceitualmente o estudante estará correto. Assim, o que ocorre é que perceber as unidades é uma abstração reflexionante, mas depois de encontrar uma resposta sem sentido e ai dar-se conta das unidades e corrigir o erro, também é uma abstração reflexionante; no entanto, estes dois exemplos de abstrações estão em patamares de reflexionamento diferentes.

E a abstração refletida e muito pouco demonstrada pelos estudantes, às vezes em generalizações matemáticas (demonstração lógicas-argumentativas), que tem uma definição distinta da dada por Piaget a seguir.

A ideia de generalização de Piaget (1973)[28] é tornar conhecido o desconhecido e esta pode ser indutiva 
e construtiva, sendo a primeira indutiva decorrente da abstração empírica, e a construtiva da reflexionante e refletida.

Assim, aprendizagem cooperativa, para Bona (2012)[5], é uma forma de aprender a aprender por meio de atividades (ações) - interações, sejam estas com objetos ou com estudantes/professor, baseadas em regras autônomas e um respeito mútuo entre todos que fazem parte deste coletivo da aprendizagem, mas tais interações tem de estabelecer uma troca como uma operação do tipo correspondência, complementaridade e/ou reciprocidade, segundo Piaget (1973)[28].

E nessas interações estão presentes as ações que proporcionam a abstração do estudante, seja empírica, reflexionante ou refletida, onde tais interações, num primeiro momento, parecem apenas trocas sociais, mas são trocas intelectuais, tanto coletivas como individuais. Assim, a aprendizagem cooperativa possibilita a conceituação, a generalização e logicamente a construção do pensamento formal do estudante.

\section{Método, Procedimento e Material}

Primeiramente esta seção tem a intenção de justificar a escolha da metodologia unicamente qualitativa desta pesquisa, que é uma pesquisa-ação, de Barbier (2004)[1], depois explicar o procedimento de condução da pesquisa e da aula, os apontamentos do que são os materiais e algumas análises destes materiais.

Destaca-se que não foi realizada tabulações e nenhuma forma de dados quantitativo por não ser o objetivo deste trabalho. Mas pode-se apontar que a metodologia proporciona uma boa análise do processo de aprendizagem dos estudantes como é o foco desta pesquisa, assim possibilitando com facilidade a validação da aprendizagem de matemática para a posterior avaliação do professor. Além disso, segundo Bona (2010)[4] é plenamente possível o professor explorar este tipo de análise nas suas avaliações e atividades cotidianamente, porque é um olhar mais qualitativo sobre o processo de aprendizagem, no caso, da matemática, por exemplo, a leitura detalhada da resolução de um problema de matemática.

A pesquisa-ação proporciona um espaço de problematização das ações e situações que ocorrem na Escola Básica, tanto pelos professores de matemática como pelos estudantes, sendo esta metodologia uma técnica que possibilita identificar os problemas da prática, e assim como todos os agentes envolvidos, professores e estudantes, traçar soluções para os problemas, segundo Bona (2012)[5].

Além disso, esta metodologia contempla a proposta docente dialogada de Freire (1996)[4], e entende os estu- dantes como sujeitos participantes, ou seja, ativos do processo de pesquisa que é o de aprendizagem de cada um, ou seja, a professora ora é pesquisadora, ora professora, e o estudante, também é estudante e ora pesquisador, sendo seus papéis entrelaçados e necessariamente indissociáveis para uma educação de qualidade inserida numa cultura digital onde a mudança é um elemento permanente, também para Piaget (1973; 1977; 2002)[27,28,29]. E para Franco (2005, p. 485)[1], “se alguém opta por trabalhar com pesquisa - ação, por certo tem a convicção de que pesquisa e ação podem e devem caminhar juntas quando se pretende a transformação da prática".

Nesse cenário da pesquisa-ação, o espaço de aprendizagem digital da matemática no caso o Facebook é um espaço de estudo realmente dos estudantes, pois a organização do grupo é fechada, apenas estes visualizam e a professora de matemática, e estão no contrato as regras de funcionamento.

As atividades realizadas neste espaço digital não são avaliadas de forma somativa, ou seja, não "valem nota", porém a professora destina 2 horas semanais online para discutir por chat ou fórum com os estudantes o que eles desejarem, pois o propósito deste espaço digital é realmente despertar a curiosidade dos estudantes para aprender a aprender matemática.

Os estudantes do $2^{\circ}$ ano do IFRS-Campus Osório têm apenas dois períodos de matemática por semana em função da inserção das disciplinas técnicas do curso técnico de médio integrado em informática, sendo num total de 1h50min por semana, para trabalhar todos os conteúdos que se orienta os Parâmetros Curriculares Nacionais de Matemática-PCN (Brasil, 1999)[20], juntamente com as mais 10 disciplinas do ano, como: português, inglês, algoritmos, introdução a informática, geografia e outras.

Além da aula presencial os professores do IFRS destinam um horário de estudos orientados aos estudantes no turno inverso para atendimento de dúvidas, que geralmente é de 2 horas semanais por professor para cada disciplina e ano escolar.

No caso desta turma de $2^{\circ}$ ano, os estudantes têm 2 horas de estudos orientados presencial por semana, e mais 2 horas de estudos orientado online, ou seja, quando a professora de matemática está online no Facebook a disposição dos estudantes, quando estes nada questionam, a mesma lê as resoluções feitas pelos estudantes em momentos diversos, e posta comentários na forma de pergunta geralmente para instigar os estudantes e retomarem a discussão.

A professora-pesquisadora explora tanto os documentos anexos no espaço, como as formas de comunicação tipo fórum e chat que são disponibilizadas pelo Facebo$o k$, e que tudo fica registrado, por tempo indeterminado, 
no próprio espaço a todos os membros deste grupo, no caso a professora de matemática e os 24 estudantes do $2^{\circ}$ ano.

A figura 1 é um print screen do grupo denominado pelos estudantes no Facebook de 'I 201 - Matemática', e esta também mostra, por exemplo: o aplicativo Docs (usado pelos estudantes para anexar documentos de diversos formatos), a ferramenta eventos que os estudantes adotaram como agenda das atividades de matemática, a possibilidade de chat coletivo e o modelo de ambiente virtual característico do Facebook que é um fórum.

Além deste elementos sobre as tecnologias digitais, a figura 1 evidencia que os estudantes se apropriam das tecnologias digitais online como o uso do chat, também dos softwares como Paint para fazer as representações interpretações dos problemas. E ainda, verifica-se que os estudantes estão envolvidos com este espaço, ou melhor, com o seu processo de aprendizagem de matemática, em diversos horários, e não apenas na sala de aula, como uma estudante postou em 3 de março de 2012 às 7h34:
"Acesso nossa sala online no Face a toda hora e até antes da aula presencial pq estudo por ali. E penso que estar online não é estar distante, mas mais perto $d q$ nunca...".

Os estudantes são codificados pela letra inicial do seu nome, e se ocorrer de nomes repetidos na turma acrescenta-se a segunda letra do nome também. Todos os pais/responsáveis estavam cientes da pesquisa e os estudantes desejaram participar da pesquisa-ação.

O problema ilustrado na figura 1 é um exemplo de como os estudantes procedem no espaço do Facebook, ao pegarem a lista de exercícios proposta pela professora, os mesmos sorteiam os problemas e determinam se vão se organizar em duplas ou trios. Após esta distribuição dos problemas, cada grupo de estudantes decide como postar, fazer e resolver a questão, como no caso da estudante $Y$ que ficou responsável pelo problema 1 da lista de Modelagem sobre Geometria Espacial juntamente com seus colegas $\mathrm{C}$ e $\mathrm{K}$.

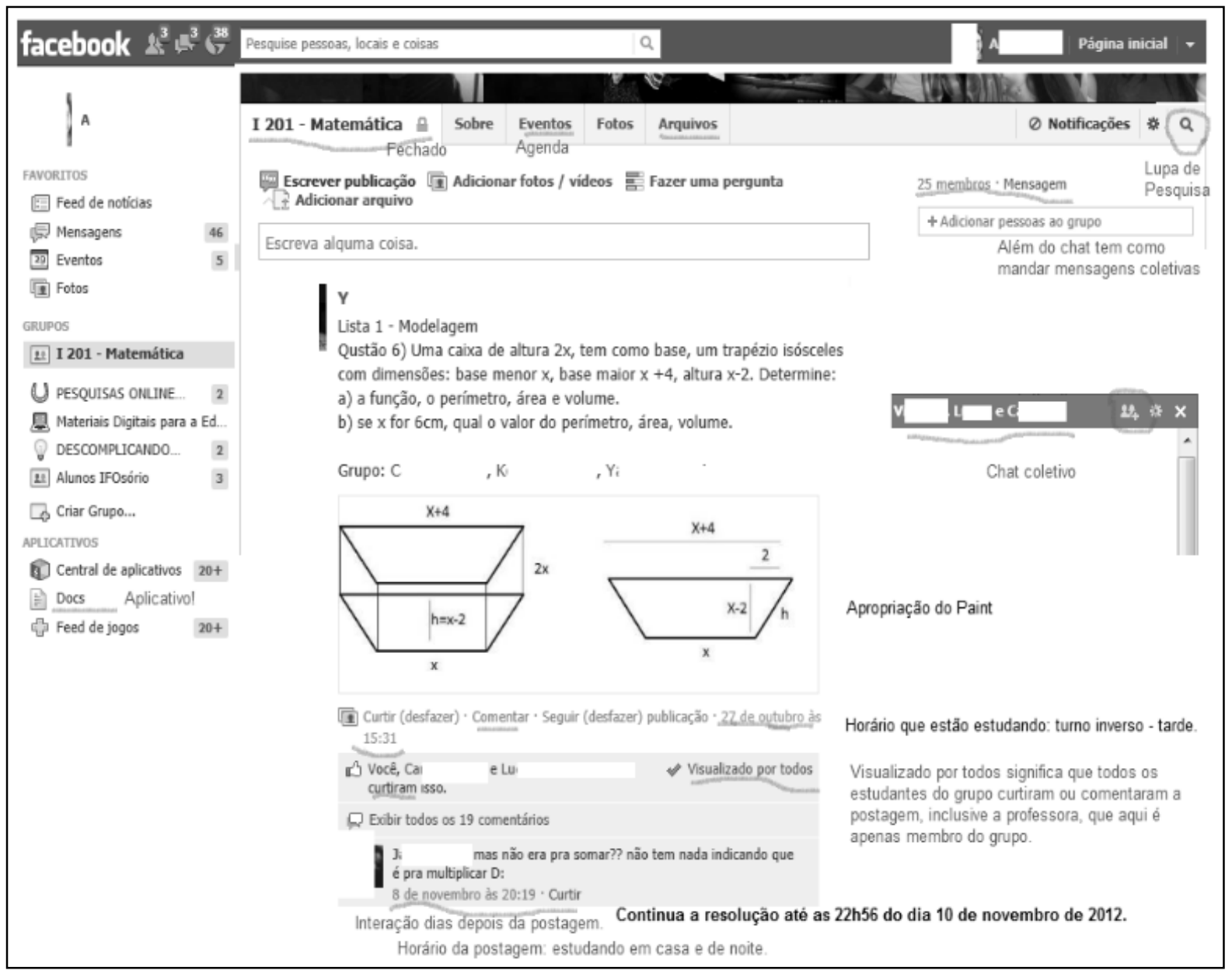


Figura 1 : Print do Grupo do Facebook com apontamentos.

A ideia do botão Curtir do Facebook no espaço de aprendizagem digital da matemática significa que os estudantes concordam e/ou gostaram e/ou entenderam a resolução/postagem/ideias expressa, segundo definição dos 24 estudantes desta turma, após pesquisa realizada pelos mesmos no Facebook fazendo uso do recurso "fazer uma pergunta" disponibilizado nesta rede social.

Da mesma forma, os estudantes definiram e diferenciaram a rede social do espaço de aprendizagem digital da matemática, pois para estes estudantes:

"a rede social é um lugar livre, onde o objetivo é compartilhar, e o Face como sala de aula é um lugar divertido mas sério pq há um objetivo claro para todos que é trocar ideia de matemática para aprender e saber fazer os problemas, e neste podemos fazer do nosso jeito a toda hora, e até no iPad....mas na prova não podemos escrever com internetês como escrevemos aqui..."

Não é objetivo deste artigo e nem desta pesquisaação, mas é evidente a constatação do fato de que os estudantes mostram diferenciar os momentos de aprendizagem, como a forma de se escrever na internet não é a mesma de se fazer em uma prova/documento de avaliação de matemática, por exemplo.

E esta apropriação está presente na linguagem simbólica da matemática, em que, por exemplo: os estudantes quando desejam extrai a raiz quadrada de um número usam a expressão em inglês sqrt e escrevem a palavra raiz quando desejam representar um número irracional, devido à falta de símbolo $\sqrt{ }$.

Outro exemplo, é a apropriação do conceito de matemática e a criação de uma linguagem que é compreendida no grupo, por exemplo, quando se faz a fatoração de um número para se extrair a raiz quadrada, os estudantes escrevem:

" $Y$ : sqrt $72=$ ? fatorar: $72 / 2=36 / 2=18 / 2=9 / 3=3 / 3=1$ dai sqrt $72=2 * 3 \sqrt{2}=6 \sqrt{2}$;

$G$ : mas se o conjunto de resposta for racionais temos $d$ extrai a raiz aproximada de $2 \mathrm{c} / 1,4 \mathrm{p} /$ dar a resposta $q$ seria $6.1,4=8,4$;

$P$ : eu penso igual vcs, mas acho q a sora não vai entender estes $=e$ vai dizer $q$ não entendeu como ela tem $d$ fazer pelo contrato. E o domínio é reais positivos, mas como é medida não se pode chegar numa loja e comprar Graiz d 6 m d cordão, ne?".

Nessa transcrição pode-se perceber a interação por cooperação entre os estudantes Y e G, e uma cooperação 40 de correspondência e de complementaridade, ou seja, a correspondência se verifica quando o estudante $\mathrm{G}$ concorda com Y e a complementaridade quando $\mathrm{G}$ complementa a resolução de Y. Destaca-se que todas as transcrições são literais e contemplam os erros e as codificações dos estudantes.

Já a interação de P com os demais colegas é de cooperação por reciprocidade, porque além de concordar com os colegas ele explica e justifica seu ponto de vista, assim defendo sua resposta de forma a complementar a resolução dos colegas.

E na interação de $\mathrm{P}$ pode-se perceber também a relação de colaboração com a professora num primeiro momento, e depois a certeza que a professora vai cooperar com os estudantes devido a clausula do contrato disciplinar/didático que diz:

"... sempre a professora deve perguntar quando não entender antes de dar errado...".

A interação dos estudantes no espaço de aprendizagem digital da matemática - Facebook de forma cooperativa é intensa e apresenta ótimos resultados de aprendizagem dos conceitos de matemática, como se pode ter indicativos já nas transcrições acima.

Desta forma, volume de material produzido por estes estudantes no Facebook, apenas durante um trimestre do ano, que contemplava os conteúdos de Trigonometria no triângulo retângulo e no círculo, e de Geometria Plana, é enorme, aproximadamente 400 páginas A4 sem margens de problemas resolvidos e selecionados por print screen.

Logo, foi preciso fazer um recorte que neste caso se seleciona a resolução dos problemas de matemática postados pelos estudantes, decorrentes de listas de exercícios propostas pela professora ou de pesquisas feitas pelos estudantes. Aponta-se que estas análises podem ser desenvolvidas com bastante frequência pelo professor e até cotidiana, porque é um olhar mais qualitativo, basta conhecer a teoria da abstração do Piaget.

A seção a seguir mostra um estudo particular dos dados em que o objetivo é mostrar que a abstração refletida está presente na generalização dos conceitos de matemática, ou seja, que o estudante ao resolver um problema de matemática, num primeiro momento através de problemas anteriores de forma numérica e aplicada, agora resolvem com problemas mais gerais, que necessite a verificação da conceituação geral a qualquer problema que se aplique essas hipóteses formuladas.

Geralmente, segundo D' Ambrosio (1996)[13], os estudantes não gostam dos problemas em que os dados 
são algébricos (letras), devido a dificuldade de interpretação do que fazer e também de que conceitos de matemática precisa-se para construir este outro conceito solicitado no problema. Paralelamente, segundo Bona (2012)[5], os estudantes divertem-se com estes problemas quando resolvem de forma cooperativa e tendo a ação do professor como um questionador, pois as "letras" são codificadas por estes estudantes e assim tem um significado no contexto do problema.

A ação docente neste espaço digital é importante segundo os estudantes pelo fato de que:

"saber que a professora está ali olhando e sempre tentando entender o que estamos fazendo, faz com que a gente sinta-se seguro, e sendo orientado. Já que quando a sora não entende ela tem obrigação pelo contrato de perguntar e não de dar errado, só depois de perguntar para o grupo de alunos que fez".

\section{Abstração Refletida presente na ge- neralização de matemática}

A abstração refletida requer a tomada de consciência do estuante sobre sua interação, e geralmente é posterior a uma sequencia de abstrações reflexionantes, em que a cada ação o reflexionamento e a reflexão vinham se desenvolvendo em progresso.

Contudo, o que caracteriza o pensamento formal é a reflexão, e esta é proporcionada pela aprendizagem cooperativa. Mas esta aprendizagem cooperativa é possibilitada pelo espaço de aprendizagem digital da matemática, no caso desta turma o Facebook.

Então, o Facebook se estabelece como meio e a aprendizagem cooperativa como forma para mobilizar os estudantes a aprender a aprender matemática, que pode ser verificado por Bona (2012)[5] através da leitura das resoluções dos problemas de matemática à luz das abstração reflexionante conceito definido por Piaget (1977)[27].

As interações entre os estudantes no Facebook de forma cooperativa viabilizam aos estudantes reflexionamentos mais rápidos e quando estes são questionados pelos estudantes via chat as reflexões dos estudantes progridem em na construção de um conceito como uma espiral, e nesta espiral tem-se no plano horizontal a cooperação e no vertical a abstração reflexionante intercalada a empírica até a refletida, segundo Bona (2012)[5].

A seguir transcreve-se as interações dos estudantes em fórum no Facebook por um grupo de estudantes, que ao longo de 3 dias, envolve todos os colegas da turma.

As interações são os passos da resolução de problemas postados por curiosidades dos colegas sobre trigo- nometria no triângulo retângulo em que se buscam justificar as relações trigonométricas dos ângulos $30^{\circ}, 45^{\circ} \mathrm{e}$ $60^{\circ}$.

$\mathrm{Na}$ análise da resolução deste problema pode-se perceber que para os estudantes fazer demonstrações em matemática implica fazer uso de variáveis (letras), enquanto que neste caso basta escolher os triângulos que contenham os ângulos que se deseja.

Postagem inicial do estudante P: "Dado um quadrado de lado L. Demonstre o valor das razões trigonométricas para o ângulo de $45^{\circ}$ (tirei este problema de um livro de matemática da biblioteca, só dizia isso)"

M:"Se é quadrado então a diagonal divide este em 2 triângulos retângulos isósceles, pq ângulos alternos opostos são iguais, e dai pela soma de 180 dá que é 45 cada".

P: "fazendo pitágoras temos $q$ a diagonal é $L^{*}$ raiz d $2 "$.

O estudante P coopera primeiramente por correspondência e na sequência por complementariedade, pois continua a resolução do colega $\mathrm{M}$.

$\mathrm{O}$ estudante $\mathrm{M}$ extrai do quadrado os elementos que precisa para encontrar o triângulo retângulo que necessita para dar sequencia a resolução, nessa ação num primeiro momento se observa uma abstração empírica, baseada a sua ação com o objeto, e depois uma abstração reflexionante, porque coloca elementos ao quadrado e extrai elementos que não estão ali presentes por si só.

T: "e seno é cateto oposto / hipotenusa, então é $L / L *$ raiz d 2 q racionalizando da $(L *$ raiz de 2$) / L * 2, q \dot{e}$ igual ao cosseno, e logo tang $=1 "$.

M: "organizei as contas um pouco diferente mas cheguei nos mesmos resultados que vc, $T^{\prime \prime}$.

P: "eu entendi o que $T$ fez, e fiz primeiro cosseno, e tb deu, etanto faz como começa ne?"

O estudante $\mathrm{T}$ coopera com os colegas e resolve matematicamente segundo uma linguagem que entende ser compreendida por todos os colegas e a professora no espaço do Facebook, e este estudante se apropria das reflexões de seus colegas, e para este proporciona novos reflexionamentos, com outros elementos, e com esta nova organização e totalidade se estabelece nova reflexão. Esse processo de aprendizagem desperta a curiosidade do colega $\mathrm{M}$ em descobrir para outros ângulos.

Nas últimas três interações, sendo uma de cada T, M, e $\mathrm{P}$, verifica-se a cooperação por reciprocidade, pelo fato dos estudantes terem pontos de vista diferentes, mas cada um entende a resolução dos demais, e a resolução coletiva de todos, sendo esta cooperação a forma mais comple- 
xa e a que proporciona aos estudantes um processo de abstração mais dinâmico e rápido na construção dos conceitos de matemática, segundo Bona (2012)[5].

A finalização dada pelo estudante $\mathrm{T}$ que foi construída com seus colegas é um exemplo de que a abstração refletida ocorre quando se busca generalizações construtivas que são possibilitadas por problemas que levam as demonstrações conceituais, que é o pensamento formal de matemática.

M: "mas se pensar em como mostrar o seno de 30, temos que pensar em figura plana que tenha este ângu$l o "$.

Ca: "legal, sempre sen e cos de $45^{\circ}$ será raiz 2 sobre 2, $p / q q$ triângulo retângulo em $q$ os ângulos necessariamente serão $45^{\circ}$.

O estudante M propôs um incremento no problema de $\mathrm{P}$, e os demais colegas sentem-se interessados em resolver, sendo isto uma evidência de que os estudantes estão aprendendo a aprender com ações de autonomia, ou seja, a ideia de aprender a aprender, segundo Piaget (1977)[27], se traduz pela a capacidade de refletir, analisar e tomar consciência do que se sabe, dispondo-se a mudar os próprios conceitos, a ação de buscar novas informações, substituir velhas verdades, adquirir novos conhecimentos.

Ainda, aprender e saber realizar, fazer, construir, agir, segundo Morin (2008)[22]; e conhecer e compreender as relações, e atribuir significados as coisas, levando em conta o atual e o explicito, também passado, e o possível e o implícito, real e virtual, para Bona (2010)[4].

D: "o triângulo equilátero tem $60^{\circ}$, e o hexágono $t$, mas ele é composto de triângulos". do.."

P: "tb pensei como vcs, bah ainda bem q não tá erra-

$\mathrm{O}$ estudante $\mathrm{P}$ expressa sua opinião e receios com relação as suas ideias para resolver o problema de matemática, sendo esta uma ação positiva, porque o estudante mostra entender que o erro faz parte do processo de aprendizagem, e que este receio de fazer errado é compartilhado e amenizado com os colegas no espaço digital do Facebook.

M: "pensar no triângulo equilátero com lado L, traça-se a altura pelo vértice na base, que forma $90^{\circ}$ por definição (ou construção) de altura".

A interação do estudante $M$ cooperativa com os demais colegas aponta um reflexionamento e um reflexão clara e necessária a resolução formal do problema, pelo fato de que este percebe que tem de encontrar o triângulo retângulo que tenha um ângulo de $30^{\circ}$ ou de $60^{\circ}$. Esta busca pelo triângulo certo é uma prova em matemática, muito bem justificada pelos estudantes na sua resolução que segue cooperativamente com $\mathrm{T}$ e $\mathrm{D}$, sendo então ações cooperativas que apontam a abstração refletida na construção dos conceitos de matemática.

T: "divide base no meio, pq é triangulo equilátero e a altura é igual a mediatriz..."

D: "e os ângulos são $60^{\circ}$, como a altura tb é a bissetriz o ângulo fica no meio que é $30^{\circ}$ ".

Encontrado o triângulo com o ângulo desejado, a estudante $\mathrm{Ca}$ coopera por complementariedade, além da correspondência, pois dá continuidade à resolução.

Ca: "agora o pitágoras justifica tudo...".

$\mathrm{T}$ : "isso aplica pit para achar $h$, e no triangulo retângulo e temos $q$ sen é $(L / 2) / L=1 / 2$ " 3/2) L"

M: "faz pit dá $L^{\wedge} 2=(L / 2)^{\wedge} 2+h^{\wedge} 2$ que dá $h=($ raiz

Ca: "hum...meu fiz com cabeça e já ficou $\mathrm{h}=$ sqrt $(\mathrm{L}$ $\mathrm{L} / 4)=\operatorname{sqrt}((3 \mathrm{~L})) / 2 "$

As últimas interações de T, M e Ca apontam uma linguagem de matemática escolhida pelos estudantes para resolver os problemas no Facebook, e a troca de formas de resolver entre $\mathrm{M}$ e $\mathrm{Ca}$, por reciprocidade já que ambos se entendem.

Cabe destacar que a problemática da linguagem simbólica matemática é importante, e é parte da aprendizagem dos estudantes, porém mesmo com esta limitação deste espaço os estudantes encontram estratégias de superar, e em avaliações, como provas em sala de aula, e em suas atividades de sala de aula, escritas à mão ou até digitas num editor da escrita matemática correta os estudantes a fazem, e assim mostram compreender a linguagem matemática correta e sua adaptação quando não existem os símbolos certos, assim como conversam e estudam com outros colegas, que não deste grupo específico, de forma certa. Inclusive em função desta escrita matemática, muitas vezes, os estudantes resolvem com uma linguagem alternativa, como chamam, e depois, passam a limpo, e anexam o arquivo no Facebook via aplicativo Docs, também partilhado no grupo e possível de edição, sendo então a solução, dada pelos estudantes a esta limitação do Facebook.

$$
\mathrm{D} \text { : "cos de } 30=h / L \text { que só manipula e o de } 60^{\circ} \mathrm{td}
$$
igual". 
O estudante D evidencia uma tomada de consciência quando cita que basta agora "manipula" para se encontrar a relação presente nas "tabelas dos livros", como alguns estudantes costumam dizer antes de resolver este problema proposto por $\mathrm{P}$.

$\mathrm{Y}$ : "os domínio das letras são os reais e geralmente as medidas de geometria plana são com duas casas decimais...aproximar raízes..."

O estudante Y propõem uma outra discussão quando ao contexto das variáveis do problema, e inclusive discute a necessidade da aproximação do numero irracional expresso em raiz quadrada. Este fato é também uma abstração refletida.

P: "isso Ca seria se o problema tivesse contexto, como o exercício q postei é apenas para mostrar e assim conferir com a tabela do notáveis, entende?"

A resposta do estudante $\mathrm{P}$ a $\mathrm{Y}$ é uma outra reflexão proporcionada pela cooperação, e que leva aos dois uma abstração refletida, num contexto formal de resolução.

T: "bem q a sora disse q não precisava decorar a tabela que meu primo falou do tais ângulos notáveis".

$\mathrm{O}$ estudante $\mathrm{T}$ aponta sua reflexão sobre seu próprio processo de aprendizagem de matemática, e da necessidade de se aprender matemática. Fato este que é fundamental aos estudantes para que eles se interessem pelas aulas de matemática e sintam que as ferramentas de matemática são importantes para a vida de uma forma geral, como no trabalho, e até em disciplinas técnicas do curso como algoritmos, no contexto da Informática.

P: "p/pensarmos nos ângulos de 0, 90, 180, 270 e 360 tem q pensar o círculo trigonométrico q nunca vi, ainda bem a sora abriu um espaço digital para revisar estas coisas de matemática ne?"

Novamente o estudante P está propondo aos seus colegas novas pesquisa e construções, que são dadas sequencia num outro momento pelos estudantes, contemplando mais colegas desta vez.

Ainda nesta interação o estudante destaca a importância do espaço digital com os colegas para que estes aprendam conceitos não aprendidos antes, e/ou revejam conceitos já trabalhos em anos anteriores. Tal tomada de consciência do estudante é fundamental para sua própria participação nas aulas de matemática e envolvimento com os problemas postados por outros colegas no Facebook.
Ca:"o melhor P e q a gente faz junto, pq se um não sabe como continua o outro ajuda, e tem todo tempo do mundo pq tudo ficar armazenado no face só para nossa turma...".

A estudante Ca menciona sua satisfação em aprender de forma cooperativa por meio do espaço de aprendizagem digital da matemática, que este grupo adota o Facebook, e também aponta qualidades do espaço digital escolhido pela sua turma.

Observando as interações acima se constata, como apontado no decorrer da transcrição, os estudantes aprendendo por cooperação, nos três tipos - correspondência, complementariedade e reciprocidade e paralelamente se analisa as abstrações empíricas, reflexionantes em graus, até a reflexiva.

Este é apenas um exemplo de que os estudantes cooperando conquistam a abstração refletida sobre um ou mais conceitos de matemática, pois existem muito exemplos, e alguns extremamente complexos para apresentar num artigo que tem limite de páginas.

Paralelamente a esta análise que relaciona cooperação e abstração reflexionante, se constata a aprendizagem de matemática, como pode ser verificado no exemplo supracito, e segundo Bona (2012)[5], os estudantes que estudam neste espaço digital cooperativo usam/aplicam novamente estes conceitos de matemática em outros problemas de matemática, e também na área da informática, em disciplinas como: algoritmos e programação, e nas demais pesquisas que os estudantes realizam por interesse pessoal.

\section{Considerações Finais}

O artigo apresenta definições sobre os elementos mobilizadores/atrativos para os estudantes: espaço de aprendizagem digital da matemática e a aprendizagem cooperativa. Além disso, um possível espaço de aprendizagem digital da matemática adotado por estudantes do ensino médio que é a rede social Facebook.

A aprendizagem cooperativa é possibilitada pelo espaço de aprendizagem digital da matemática, e esta forma de aprender a aprender, analisada sobre as conceituações de abstração de Piaget (1977)[27], apontam a construção dos conceitos de matemática, não somente de forma aplicada e/ou numérica, mas por meio de prova matemática sob um pensamento formal, segundo Bona (2012[5]), mas que neste artigo se apresenta uma aplicação das razões trigonométricas e do Teorema de Pitágoras apontando o processo de construção conceitual ainda não concluído, porém em momentos de generalizações, partindo de 
deduções numéricas, nem sempre verdadeiras, e que os estudantes discutem entre si.

Os estudantes mobilizados aprendem a aprender com muito interesse e curiosidade, buscando novos problemas de matemática para resolver com os colegas, e estes estão sempre esperando a assistência da professora, mesmo que indireta, pois a professora não pode estar todo o tempo online, mas o diálogo entre os estudantes e a professora é fundamental a "liberdade" dos espaço digital.

$\mathrm{O}$ contrato didático/disciplinar estabelece as condições básicas para que uma rede social possa se um espaço de aprendizagem digital da matemática, e também conduz a premissa de paridade, segundo Piaget (1973)[28], para

\section{Referências}

[1] R. BARBIER. A Pesquisa-Ação. Série Pesquisa em Educação. Brasília: Liber Livro Ed, 2004.

[2] A. S. D. BONA. Ações de Investigação na Aula de Matemática. In: XV Encontro Nacional de Educação Matemática, Curitiba, Paraná, 1- 15, 2013.

[3] M. V. A. BASSO. Espaços de aprendizagem em rede: novas orientações na formação de professores de Matemática. Tese (Doutorado). Programa de Pós-Graduação em Informática na Educação. Porto Alegre: UFRGS, 2003.

[4] A. S. D. BONA. Portfólio de Matemática: um instrumento de análise do processo de aprendizagem. Dissertação (Mestrado em Ensino de Matemática) - Programa de Pós- Graduação em Ensino de Matemática. Porto Alegre: UFRGS, 2010 .

[5] A. S. D. BONA. Espaço de Aprendizagem Digital da Matemática: o aprender a aprender por cooperação. Tese (Doutorado em Informática na Educação) - Programa de Pós- Graduação em Informática na Educação. Porto Alegre: UFRGS, 2012.

[6] A. S. D. BONA; L. D. FAGUNDES; M. V. A. BASSO. A cooperação e/ou a colaboração no Espaço de Aprendizagem Digital da Matemática. In: RENOTE - Revista Novas Tecnologias na Educação, 9(2), 1-11, 2011.

[7] A. S. D. BONA; L. D. FAGUNDES; M. V. A. BASSO. Mathematics Digital Learning Space: learning how to learn by cooperation. In: XVII que ocorra a cooperação, e as cláusulas deste contrato construído coletivamente cumpre os requisitos do respeito mútuo e das regras autônomas necessárias para que se estabeleça a cooperação entre todos.

Então, o artigo socializa a pesquisa-ação realizada e alguns dos seus resultados, além de viabilizar um espaço de reflexão ao leitor sobre alguns conceitos como os definidos e os entrelaçados na metodologia como meios e formas de analisar e compreender o processo de aprendizagem dos estudantes mobilizados pelo aprender a aprender matemática no espaço digital e cooperativo.

TISE 2012 - XVII Congresso Internacional de Informática Educativa- Nuevas Ideas en Informática Educativa, Santiago do Chile, 8,148-153, 2012a.

[8] A. S. D. BONA; L. D. FAGUNDES; M. V. A. BASSO. Facebook: um espaço digital de aprendizagem cooperativa da Matemática. In: RENOTE - Revista Novas Tecnologias na Educação, 10 (2), 1-11, 2012b.

[9] M. C. BORBA; M. G. PENTEADO. Informática e Educação matemática. Belo Horizonte: Autêntica, 2001.

[10] BORBA, M. C.; VILlarREAL, M. V. Humans-With-Media and the Reorganization of Mathematical Thinking: information and communication technologies, modeling, experimentation and visualization. v. 39, New York: Springer, 2005.

[11] BRASIL. Ministério da Educação. Secretaria de Educação e Cultura. Parâmetros Curriculares Nacionais: ensino médio. Brasília: MEC/SEMTEC, 4v., 1999.

[12] G. D. CAMARGO; L. BAMPI. A Maratona dos Poliedros - O professor cansado e a diferença do igual. In: F. E. MOELLWALD; L. BAMPI (orgs). Iniciação à docência em Matemática: Experiências e outros escritos. São Leopoldo: Oikos, 19-34, 2011.

[13] U. D’AMBROSIO. Educação Matemática: da teoria à práxis. Coleção Perspectivas em Educação Matemática. Campinas, SP: Papirus, 1996.

[14] Ed. DUBINSKY; P. LEWIN. Reflective abstraction and mathematics education: The genetic decomposition of induction and compactness. In: The Journal of Mathematical Behavior, 5 (1), Apr, 55-92, 1986. 
[15] L. C. FAGUNDES. Informática e o processo de aprendizagem. In: Revista Psicologia: reflexão e crítica. Porto Alegre: UFRGS, 5 (1), 1993.

[16] D. FIORENTINI; S. LORENZATO. Investigação em educação matemática: percursos teóricos e metodológicos. Coleção Formação de Professores. Campinas: Autores Associados, 2007.

[17] M. GOOS, et al. Perspectives on technology mediate learning in secondary schoolmathe matics classrooms. In: Mathematical Behavior, 22, 73-89, 2003.

[18] S. GRINESKI. Questioning the Role of Technology in Higher Education: Why is this the Road Less Traveled? In: The Internet and Higher Education, 2 (1), 45-54, 1999.

[19] D. S. HOFFMANN. Modalidade 1:1: tecnologia individual possibilitando redes de fluência digital. Tese (doutorado). UFRGS - Programa de Pós-Graduação em Informática na Educação. Porto Alegre: UFRGS, 2011.

[20] INEP. Instituto Nacional de Estudos e Pesquisas Educacionais Anísio Teixeira. SAEB -Sistema de Avaliação da Educação Básica, 2011. Disponível:

http://www.inep.gov.br/basica/saeb/default.asp.

[21] A. D. MORAIS. Fórmula (-1): Desenvolvendo Objetos Digitais de Aprendizagem e Estratégias para a Aprendizagem das Operações com Números Positivos e Negativos. Dissertação (Mestrado em Ensino de Matemática) - Programa de PósGraduação em Ensino de Matemática. Porto Alegre: UFRGS, 2010.

[22] E. MORIN. O Método 3: O conhecimento do conhecimento. 5a ed. Porto Alegre: Sulina, 2008.

[23] C. M. I. NOGUEIRA; R. M. PAVANELLO. A Abstração reflexionante e a Produção do Conhecimento Matemático. In: Revista Bolema, Rio Claro (São Paulo), 30, 111-130, 2008.

[24] J. PALFREY; U. GASSER. Nascidos na era digital: entendendo a primeira geração dos nativos digitais. Porto Alegre:Artmed, 2011.

[25] S. PAPERT. A Máquina das crianças. Porto Alegre: Artmed, 1994.

[26] O. PETERS. A educação à distância em transição. São Leopoldo: Unisinos, 2009.
[27] J. PIAGET. Abstração Reflexionante: relações lógico - aritméticas e ordem das relações espaciais. Porto Alegre: Artmed, 1977.

[28] J. PIAGET. Estudos Sociológicos. Rio de Janeiro: Forense, 1973.

[29] J. PIAGET. Abstração Reflexionante: relações lógico - aritméticas e ordem das relações espaciais. Porto Alegre: Artmed, 1977.

[30] M. J. B. RIBEIRO, J. P. PONTE. A formação em novas tecnologias e as concepções e práticas dos professores de matemática. In: Quadrante, 9 (2),2-26, 2000.

[31] F. F. SERRES. Concepção e Prática de Ensinar Matemática nos Anos Iniciais do Ensino Fundamental: estudo de caso em um curso de Pedagogia a distância. Dissertação (Mestrado). Programa de Pós- Graduação em Educação. Porto Alegre: UFRGS, 2010.

[32] C. SPAUDING; D. LAKE. Interative effects of computer network and student characteristics on students'writing and collaborating. Paper presented at The Annual Meeting of American Educational Research Association, Chicago, IL, April 1991, as reported in Riel, 1992.

[33] L. TROUCHE. From artifact to instrument: mathematics teaching mediate by symbolic calculators. In: Interacting with Computers, 15, 783-800, 2003.

[34] J. VALENTE. Aprendendo para a Vida: O uso da Informática na Educação Especial. In: M. P. Freire e J. A. Valente (orgs). Aprendendo para a Vida: Os Computadores na Sala de Aula. São Paulo: Cortez, 2001. 